\title{
Functions and Functioning in Aldo Leopold's Land Ethic and in Ecology
}

Forthcoming in Philosophy of Science in the PSA 2017 symposia volume. The final published version may have some small differences from this version.

\author{
Roberta L. Millstein \\ Department of Philosophy \\ University of California, Davis \\ 1 Shields Ave. \\ Davis, CA 95616 \\ RLMillstein@UCDavis.edu
}

\begin{abstract}
I examine the use of the term function in Aldo Leopold's land ethic, invoked as: 1) the healthy functioning of the land community, which is dependent on 2) the maintenance of the characteristic functions of populations that are parts of the land community. The latter can be understood as referring to interactions between species that are the products of coevolution (such as parasite-host, predator-prey, etc.), and thus, in terms of the "selected effect" account of function. The performance of these functions under certain conditions maintain what Leopold took to be the healthy functioning of a land community.
\end{abstract}

Acknowledgements: Thanks to Antoine Dussault, Justin Garson, Andrew Inkpen, Chris Lean, Maureen O’Malley, and the Griesemer/Millstein Lab for helpful comments at various stages of this project. 
1. Introduction. Talk of functions and functioning ("function talk") is pervasive in ecology. What should we make of it?

Previous work on functions more generally (i.e., not necessarily specific to ecology) has elaborated various meanings of the word "function," giving rise to a variety of accounts: selected effect (Millikan 1989, Neander 1991), causal role (Cummins 1975), organizational (Mossio et al. 2009), persistence (Dussault and Bouchard 2017), etc. I will take it as a given that there are good reasons to be a pluralist about the meaning of "function" and "functioning" both in general and in ecology; these terms are used in a wide variety of ways, many of which are useful and descriptive. Nonetheless, this pluralism need not entail that every use of the terms "function" or "functioning" can plausibly be understood in terms of any account of function. Rather, it is more likely that different accounts of function are more or less appropriate for different contexts, i.e., that they do a better or worse job of capturing particular intended meanings and particular phenomena at hand.

Notably, function talk appears in environmental ethics, conservation biology, and other ecologyrelated fields. These uses embrace a normative component to "functions" and "functioning." Aldo Leopold - a 20th century forester, wildlife ecologist, conservationist, and professor - has been highly influential in all of these areas and provides a useful path for thinking about function talk in these contexts. My goal in this paper is to give an account of function that will illuminate Leopold's usage while cohering with contemporary ecology. More specifically, I will buck the consensus against using a selected effect account of function in ecology and characterize "healthy functioning" as well, drawing on biologist John Thompson's account of coevolution. 
I begin in Section 2 by clarifying the way that Leopold uses the terms "function" and "functioning." In Section 3 I explicate the controversy over using selected effects functions in ecology. In Section 4, I argue for spelling out Leopold's use of "function" in terms of coevolution (and thus the selected effects account); section 5 turns much more briefly to "functioning." In Section 6, I conclude with some potential advantages of this account.

2. Jax's Typology of Functions and Leopold's Function Talk. Jax (2005) identifies four meanings of function in ecology:

1. What happens between two objects - the process or interaction, e.g., a fox eats a mouse.

2. The functioning of a complex system of interactions - some state or trajectory of the system under consideration and the sum of those processes that sustain the system.

3. When objects are attributed a role within the system, e.g., a primary producer, a predator, a parasite.

4. The service the system provides for human beings (or other living beings).

Jax's second and third meanings in particular are helpful for understanding Leopold's meaning in several passages in "The Land Ethic" where Leopold refers to functions/functioning: "The 
velocity and character of the upward flow of energy depend on the complex structure of the plant and animal community, much as the upward flow of sap in a tree depends on its complex cellular organization. Without this complexity, normal circulation would presumably not occur. Structure means the characteristic numbers, as well as the characteristic kinds and functions, of the component species. This interdependence between the complex structure of the land and its smooth functioning as an energy unit is one of its basic attributes" (1949, 216; emphasis added).

Preceding passages suggest that these functions are related to "lines of dependency" for food and other services ("food chains") within the land pyramid, which consists of "layers" of soil, plants, insects, birds, rodents, etc. $(1949,215)$. Moreover, he speaks of the healthy functioning of the system $(1949,214)$. Leopold's use of "function" thus seems to be in terms of the functional role that different species play, such as which species eat which other species $\left(J_{a x}{ }^{\prime} \# 3^{1}\right)$; as the above passage suggests, the performance of these functions give rise to the functioning of the system (Jax's \#2). But how can we understand Leopold's use of role function and functioning more precisely? Does it map onto any of the accounts of function in the philosophical literature?

\section{Selected Effects (SE) Functions in Ecology? Recall that on Larry Wright's (1973)}

etiological account of function, "the function of $X$ is $Z$ " means:

(a) $X$ is there because it does $Z$.

(b) $Z$ is a consequence (or result) of $X$ 's being there.

\footnotetext{
${ }^{1}$ Discussion with Antoine Dussault has made me realize that there is an ambiguity to role functions. They might mean 3a) a type of activity that occurs across ecosystems, such as predatory activity or $3 b$ ) the effects of those activities, such as nutrient flow. In what follows, I focus on sense 3 a.
} 
On the selected effects (SE) version of Wright's account (e.g., Millikan 1989, Neander 1991), requirement (a) is spelled out in terms of natural selection. For example, "the function of zebra stripes is to avoid biting flies" (Izzo et al. 2014) means that zebras have stripes because they ward off biting flies - there was selection for zebra stripes in the past because they conferred an advantage in environments with biting flies - and that avoiding biting flies is a consequence of zebra's having stripes.

Leopold notes in "The Land Ethic" that it is evolution that has created the links of food chains and evolution that makes adjustments to the energy circuit. So, prima facie, it seems as though we ought to be able to understand Leopold's use of role function in terms of SE functions, assuming he was referring to natural selection specifically. Is there a way to defend this claim?

Some authors refer to an implicit consensus against SE accounts of function in ecology (e.g., Nunes-Neto et al. 2014, Dussault and Bouchard 2017). For example, Maclaurin and Sterelny (2008) contrast function in evolutionary biology (where they think the SE account is appropriate) with ecology (where they think the SE account is not appropriate). According to Maclaurin and Sterelny, function in evolution is typically understood in terms of selective history. Functions of parts/traits of organisms are those that enabled organisms to better survive and reproduce than organisms that lacked such parts/traits. However, Maclaurin and Sterelny state, ecology is different because, "no one would now defend a view of functional organization of communities modeled on the functional organization of organisms... Communities are not elements of a population of competing communities, and they do not have daughter communities that resemble 
their parents. If a selective history is necessary for communities to have organization or structure, then most assemblages of populations are not ecological systems" $(2008,114$; emphasis added).

Here, Maclaurin and Sterelny seem to be implying:

1. In evolutionary biology, selection on organisms occurs because of the functions of their traits/parts.

2. Thus, in ecology, to make sense of the function of the parts of communities (the organisms), there would have to be selection on communities.

3. However, communities do not have the characteristics to make them appropriate units of selection.

4. Thus, we cannot speak of the SE functions of the parts (the organisms).

Antoine Dussault (2018) questions premise \#3, saying that it is an empirical question and that the empirical question remains unsettled. I'm inclined to agree with that, but I think premise \#2 is also questionable — that is, it is questionable that selection must be on communities (or ecosystems) to make sense of SE functions in ecology.

4. Selected Effects Functions Via Coevolution. Another way to use selection to explain the functional roles that organisms play, without invoking selection on communities or ecosystems is coevolution, defined as "reciprocal evolutionary change between interacting species driven by natural selection" (Thompson 2005, 3). To put this in terms of SE functions would be to claim 
(roughly; I will make this more precise below) that species $X$ has functional role $Z$ because of coevolution with species $Y$. That is, species are playing the interactive roles that they do because of coevolution with other species. ${ }^{2}$

An immediate worry arises for this suggestion; Dussault and Bouchard (2017) and Dussault (2018) suggest that there are roles ("use" or "service" roles) played by organisms within communities that are not the product of selection (or evolution). For example, a rabbit can be used as food by a fox even if the rabbit has not evolved to be food for a fox or the fox evolved to control rabbit populations.

Moreover, as Jax (2010) emphasizes, a species may play many roles within an ecosystem, and those roles are context dependent and changing: “...a bird may have the function of being prey to other animals - but only if these carnivorous animals are parts of the specific system. If there are no predators in the system, the same species or even individual will not have the role 'prey"' (Jax 2010). But what is the role? We say "predator" or "parasite," but predators don't eat all other species and parasites don't parasitize all other species. For example, even lions, perhaps the archetypical predators, eat only a small number of the animal species in their habitats, especially if one focuses on the species that make up the majority of a lion's diet (Thompson 2005, 231). We need to be more specific when characterizing a species' role.

${ }^{2}$ Note: This leaves out some types of functional roles, notably that of primary producer, as well as abiotic functions. This paper will not address those roles, limiting itself to discussing the functional roles that involve interactions between biotic organisms. I leave these other topics for a future work. 
4.1. The Geographic Mosaic Theory of Coevolution. As John Thompson argues, "[m]ost species are specialized to interact with only a few other species. That certainly is not the impression one gets from thinking only about birds and mammals and trees, but these are the showy exceptions in the evolution of diversity—and even some of these groups include extreme specialists" (Thompson 1994, 121; emphasis added). Furthermore, “[t]he proportion of extreme specialists and generalists in species interactions differs among lineages and habitats, but there are many more specialists than generalists in any real sense of those words. Until recently, that has not been the prevailing view in ecological approaches to coevolution. That view, however, is changing" (Thompson 2005, 35; emphasis added).

Thompson's explanation for the prevalence of specialists over generalists is his Geographic Mosaic Theory of Coevolution, or GMTC $(1994,2005)$. According to the GMTC, species are phylogenetically conservative in their interactions, meaning that the traits used by species in their interspecific interactions are "jury-rigged" from their ancestral traits, biasing adaptation in particular directions. As a result, the members of each species are phylogenetically constrained to eat, compete against, and defend themselves against a minuscule fraction of the earth's biological diversity. Thompson further argues that, "[w]hen species are able to shift their interactions to other species, they often do so by shifting onto species that are phylogenetically close to the species used by their ancestors. For a parasite of mammals, the evolutionary options rarely include shifting to a frog as its primary host. For insects that feed on conifers, incorporation of orchids in their diets is unlikely" (Thompson 2005, 28).

Moreover, Thompson argues, the genetic bases for these interactive traits differ from population 
to population. As a consequence, different populations of the same species can coevolve with different (other) species. For example, population $\mathrm{X}_{1}$ of species $\mathrm{X}$ might coevolve with population $\mathrm{Y}_{1}$ of species $\mathrm{Y}$, while population $\mathrm{X}_{2}$ of species $\mathrm{X}$ might coevolve with population $\mathrm{W}_{1}$ of species $\mathrm{W}$. Thus, when looking just at the species level, it can appear that organisms are more generalists than they really are. It is at the population level where actual degree of specialization is revealed. In fact, Thompson argues, most species are specialists to varying degrees, with adaptations to species that are closely related to each other.

4.2. The Case of the Blister Beetle. A recent study of the blister beetle (Saul-Gershenz et al. 2018) illustrates Thompson's GMTC, although the GMTC is not cited. The study examined two populations of a parasite, Meloe franciscanus (blister beetle), one in the Mojave Desert and one in Oregon. In Oregon, the blister beetle's host is Habropoda miserabilis (dune silver bee), whereas in the Mojave Desert, the blister beetle's host is Habropoda pallida (white-faced bee). Transplant experiments showed that local beetle parasites are significantly more attractive to local male bees than nonlocal beetle parasites. The researchers found that each parasite population mimics the sex pheromones of its respective host bee; in other words, the two parasite populations have evolved divergent host-matching behaviors.

This study fits Thompson's account by showing different local populations of a species of parasite adapting to different species of bees from the same genus. The study shows the genetic basis of the behavior and also shows that one local population of the parasite cannot simply change its behavior to parasitize the other host. 
What does this case show for the issue at hand concerning role functions? Let us ask: what is the functional role of the blister beetle $M$. franciscanus? Here are some possible answers, from very general to more specific:

1. The blister beetle is a parasite.

2. The blister beetle is a bee parasite.

3. The blister beetle is a Habropoda parasite.

4. The Mojave Desert blister beetle is a white-faced bee parasite and the Oregon blister beetle is a dune silver bee parasite (both bees in the Habropoda genus) - and possibly other unknown blister beetle parasitizations.

They are all true. But 1-3 are true because 4 is true; 1-3 are generalizations of 4 . As an analogy, consider tools that have the function of being screwdrivers, even though they are different shapes and sizes. You typically cannot use a Philips head screwdriver when you need a flat-head screwdriver (although sometimes you can use a flat-head when you need a Philips head, depending on the size). So a particular screwdriver may not be able to function as a screwdriver, depending on the context, ${ }^{3}$ although we say that it is a screwdriver in virtue of the fact that it can function as a screwdriver in particular cases. This suggests that it is important to be clear about specific claims that are the basis for the more general ones; general claims can be misleading.

Thus, what makes the functional role claim, "The blister beetle is a parasite"4 true is that there

\footnotetext{
${ }^{3}$ The science-fiction sonic screwdrivers of the TV show Doctor Who notwithstanding.

${ }^{4}$ Here it might be more accurate to say "The blister beetle performs the role of a parasite."
} 
was coevolution between the Mojave Desert blister beetle and the white-faced bee as well as coevolution between the Oregon blister beetle and the dune silver bee. In other words, both populations of blister beetle underwent reciprocal natural selection to become parasites to their respective hosts, underwriting the functional role claim(s), from specific to general. This enables the use of an SE account of function. To put the point more formally, echoing Wright's original formulation, "the interactive role function of $X$ is $Z$ " means:

(a) $X$ is there because it does $Z$, i.e., species population $X$ coevolved with species population $Y$ to interact as a $Z$.

(b) $Z$ is a consequence (or result) of $X$ 's being there.

To reemphasize my point in this section, $Z$ is the specific function that $X$ was selected to have in the co-evolutionary process, which can support a variety of (potentially misleading, depending on context) functional generalizations. ${ }^{5}$

4.3. Potential Concerns. There are at least three possible points of controversy with respect to my arguments here. One is that I use the SE account in an unusual way - instead of a trait of the organism having a function, I refer to the whole organism as having (or perhaps more accurately, performing) a function. But is this a reasonable deviation? Importantly, nothing in Wright's original account seems to preclude it, i.e., nothing in his account seems to require that $X$ be a trait. Moreover, one possible justification is that typically the whole organism has evolved to

\footnotetext{
${ }^{5} \mathrm{Cf}$. Inkpen et al. (2017) on the question of how finely functions should be individuated. Below, I emphasize that this specific function should be understood as ability.
} 
perform its role function; in the example above, the blister beetle performs the parasite role not just by attracting the host but in other respects (sticking to the male host, transferring to the female host, transferring to and developing in the nest). This might seem to have some odd consequences; for example, that because humans have traits for helping us digest food, that humans have the function of digesting food. ${ }^{6}$ However, to an ecologist that is no more odd than saying a function of a worm is to aerate soil. From an ecological point of view, these functional role claims make sense, even if they might not make sense from, say, a societal point of view.

Another potential concern is that I focus on selection due to the reciprocal functional role that organisms and their populations play in interactions, rather than communities. Again, this is nonstandard, but it's not clear that it's problematic. For instance, my approach preserves the restriction that functions should be understood in the context of a larger whole (Godfrey-Smith 1994); it just changes what we understood the relevant whole to be. ${ }^{7}$ Even so, on this view, organisms do have functions within communities, given that communities are simply webs of interactions (Millstein 2018a). Furthermore, the shift from communities to interactions as the relevant whole that functions evolve in avoids the common objection that there is no selection at the community or ecosystem level; whether there is or not simply becomes irrelevant.

A third and different sort of concern is that the example I use deals with an easy type of case (coevolution of parasite-host interactions) rather than a harder type of case (coevolution of predator-prey interactions). ${ }^{8}$ The worry seems to be that many, or at least some, predator-prey

\footnotetext{
${ }^{6}$ Thanks to Justin Garson for this point.

7 Thanks to Justin Garson for this point.

8 Thanks to Maureen O'Malley for this point.
} 
interactions are not the result of co-evolution, as when a predator begins to predate on new organisms that it had not previously interacted with. Here I think it's important to recall, following Thompson, that the one-to-one extreme specialist picture is outdated, and that one species can co-evolve with a number of other species (sometimes via different populations), with specialization coming in degrees, with no species predating on all other species, and with species tending to predate on species that are relatively phylogenetically close to each other (organisms tend to predate on species that are similar to those that they've been selected to predate on). It's also important to remember that there are all types of predators, with some (like foxes) being more flexible than others (like spiders); we want to make sure that we aren't focusing too much on the atypically flexible ones.

But to respond more directly, let us consider a particular case that will help spell out my claims further. Let's assume, as Darwin did, that there was selection on wolves to predate on deer. Darwin points out that a wolf "preys on various animals, securing some by craft, some by strength, and some by fleetness," and then imagines a situation where (in contemporary terms) changes in the deer population produce a selective pressure for wolves to run even faster (1859, 90-21). So, if Darwin's hypothetical situation were correct, we might say that the complex hunting behavior of a wolf to hunt deer, which includes its swiftness, is an SE function. But note that what has been selected for is an ability (consistent with the understanding of fitness as an ability; see, e.g., Mills and Beatty 1979). That the ability to predate on a particular species of deer might be deployed to predate on other species does not make that ability any less selected for - the ability is still the result of a historical natural selection process. Thus, it seems as though the flexibility of the selected ability should not undermine its status as an SE interactive 
role function. Although this might seem to conflict with my earlier point that we should be careful to cite the specific function, the point I am emphasizing here is that by co-evolving with a particular species population, organisms evolve specific abilities that can sometimes be deployed in multiple contexts, so just as we should be careful not to think that roles like "predator" are fully general, we should be careful to recognize that they are often not completely specific, either.

Here a further objection might be raised that I am blurring the distinction between an adaptation and what Gould and Vrba (1982) term an exaptation - a character evolved for other usages or reasons that is now being co-opted for a different role. That is, someone might object that in the example above, the swiftness of wolves while hunting is an adaptation, but that when it is deployed on other species, it is an exaptation, and that exaptations are not SE functions. Such an objection assumes that predating on other species is a "new" usage and that, despite the selective history of that usage, it should not count as an SE function. I don't know that I would grant the objection these points, but even if they are granted, it's worth recognizing that Gould and Vrba recognized secondary adaptations - cases where additional selection acts on what was formerly an exaptation. For example, some gray wolf populations predate on salmon, engaging in specific hunting behaviors (such as eating only the heads of salmon, perhaps as a means of disease avoidance; see Darimont et al. 2003); thus, it may be the case that there is direct selection for performing that specific predatory role function. In other words, co-evolution is an ongoing process, so that if a species population begins interacting with a new species population, it may 
begin co-evolving from that point forward. ${ }^{9}$

4.4. Role Functions: Taking Stock. Many organisms and populations play various functional roles that can be described with varying degrees of specificity because they have coevolved to interact in certain ways. This claim supports Leopold's notion of function, which is grounded in the interactions/interdependencies between (populations of) species. Leopold's examples of interdependencies explicitly included parasitism, as well as predations, exploitations, and services (Millstein 2018b). Importantly, this is not to deny that populations of species can play functional roles with species other than the ones they were selected to - indeed, such changes are part of Thompson's GMTC - but rather to insist that the basis of the ability to engage in these functional roles is evolutionary and to insist, following Thompson, that populations predominantly tend to interact with species that are phylogenetically close to the ones they evolved to interact with.

5. From Role Functions to Functioning. For Leopold, the functioning of the land community ${ }^{10}$ "depends on the co-operation and competition of its diverse parts" $(1949,215)$ - in other words, the very functions we have been discussing. Moreover, as noted above, Leopold sees "the characteristic numbers, as well as the characteristic kinds and functions, of the component species" as contributing to smooth functioning of the land community $(1949,216)$. Leopold further characterizes healthy functioning, where "health is the capacity of the land for self-

\footnotetext{
${ }^{9}$ In this section I've focused on predator rather than prey, but I claim that everything I've said applies to prey as well, with the relevant selected behaviors being avoidance behaviors or other ways that prey evolve to protect themselves against predators.

${ }^{10}$ Leopold's concept of "land community" combined aspects of "community" (interacting species) with "ecosystem" (matter and energy flow). See Millstein (2018a) for discussion.
} 
renewal" $(1949,221)$ and where land "is not merely soil; it is a fountain of energy flowing through a circuit of soils, plants, and animals. Food chains are the living channels which conduct energy upward; death and decay return it to the soil. The circuit is not closed; some energy is dissipated in decay, some is added by absorption from the air, some is stored in soils, peats, and long-lived forests; but it is a sustained circuit, like a slowly augmented revolving fund of life" (Leopold 1949, 216)

So, (healthy) functioning for Leopold consists in "characteristic" species in "characteristic" numbers performing interconnected "characteristic" functions, such as predator-prey, parasitehost, etc., in such a way that energy and matter continue to flow through the soil and through the other parts of the land community, with longer food chains tending to maintain cycling better by avoiding erosion, so that the land community can continue to support life over time. ${ }^{11}$ Healthy functioning for Leopold is thus akin to what today we might term persistence or sustainability; persistence, on Leopold's account, is a probable outcome of the performance of characteristic role functions in land communities with long food chains. Dussault and Bouchard (2017) argue that their view of ecological function accounts for persistence at the population and ecosystem levels; if I am right in my reading of Leopold, his understanding of function offers an explanation of persistence as well (albeit a defeasible one), but only at the ecosystem (land community) level.

6. Conclusion. I've argued that Aldo Leopold's use of "function" and "functioning" - and that

\footnotetext{
${ }^{11}$ See McShane (2014) for an alternative account of ecosystem health that deploys Wright's notion of function.
} 
of similarly-minded ecologists and environmental ethicists - can be captured by interactive role functions of species populations characterized in terms of (more or less specific) selected effects functions, via an account of coevolution in which the majority of species are neither extreme specialists nor generalists, with specialization coming in degrees. Thus, I offer a challenge to the “implicit consensus" against selected effect functions in ecology. I further argued that functioning of the land community ("ecosystem") level can be characterized in terms of the performance of role functions (i.e., the interactions of organisms from different species).

Here are some of the features of the view I have argued for. 1) It illuminates a view that is influential among environmental ethicists and conservation biologists. 2) Like Dussault and Bouchard's (2017) account, it recaptures the evolutionary role in ecology that is absent in other accounts of function and 3 ) it unites a community perspective (interactive role functions of organisms) with an ecosystem perspective (the flow of matter and energy), yet it does so while 4) utilizing a fairly traditional account of natural selection, only invoking selection at the organism level (without denying possibility of selection at other levels). 5) It doesn't preclude other accounts of function in ecology; causal role, organizational, persistence, etc., accounts of function may illuminate other uses in or aspects of ecology. If at least some of these features are desirable ones, I will have provided an understanding of "function" and "functioning" that, given Leopold's influence, can help us to understand interactive role functions in ecology and related fields. 


\section{References}

Cummins, Robert. 1975. "Functional Analysis." Journal of Philosophy 72:741-764.

Darimont, C., T. Reimchen, and P. Paquet. 2003. "Foraging Behaviour by Gray Wolves on Salmon Streams in Coastal British Columbia." Canadian Journal of Zoology 81:349-353.

Darwin, Charles. 1859. On the Origin of Species by Means of Natural Selection, or the Preservation of Favoured Races in the Struggle for Life. 1st ed. London: John Murray.

Dussault, Antoine C. 2018. "Functional Ecology's Non-Selectionist Understanding of Function." Studies in History and Philosophy of Biological and Biomedical Sciences 70:1-9.

Dussault, Antoine C., and Frédéric Bouchard. 2017. Synthese 194:1115-1145.

Godfrey-Smith, Peter. 1994. "A Modern History Theory of Functions." Noûs 28:344-362.

Gould, Stephen Jay, and Elisabeth S. Vrba. 1982. "Exaptation—a Missing Term in the Science of Form." Paleobiology 8:4-15.

Inkpen, S. Andrew, Gavin M. Douglas, T. D. P. Brunet, Karl Leuschen, W. Ford Doolittle, and Morgan GI Langille. 2017. "The Coupling of Taxonomy and Function in Microbiomes." Biology \& Philosophy 32:1225-1243.

Izzo, Amanda, Robert C. Reiner Jr, Hannah Walker, and Theodore Stankowich. 2014. "The Function of Zebra Stripes." Nature Communications 5:1-10.

Jax, Kurt. 2005. "Function and "Functioning" in Ecology: What Does It Mean?" Oikos 111:641648.

- 2010. Ecosystem Functioning. Cambridge: Cambridge University Press.

Leopold, Aldo. 1949. A Sand County Almanac and Sketches Here and There. New York: Oxford University Press. 
Maclaurin, James, and Kim Sterelny. 2008. What Is Biodiversity? Chicago: University of Chicago Press.

McShane, Katie. 2004. "Ecosystem Health." Environmental Ethics 26:227-245.

Millikan, Ruth G. 1989. "In Defense of Proper Functions." Philosophy of Science 56:288-302.

Mills, Susan K., and John H. Beatty. 1979. "The Propensity Interpretation of Fitness." Philosophy of Science 46:263-286.

Millstein, Roberta L. 2018a. "Is Aldo Leopold's 'Land Community' an Individual?" In Individuation, Process, and Scientific Practices, edited by O. Bueno, R. Chen and M. Fagan, 279-302. Oxford: Oxford University Press.

_.2018b. "Understanding Leopold's Concept of ‘Interdependence' for Environmental Ethics and Conservation Biology." Philosophy of Science 85:1127-1139.

Mossio, M., C. Saborido, and A. Moreno. 2009. "An Organizational Account of Biological Functions." British Journal for the Philosophy of Science 60:813-841.

Neander, Karen. 1991. "The Teleological Notion of "Function”." Australasian Journal of Philosophy 69:454-468.

Nunes-Neto, Nei, Alvaro Moreno, and Charbel N. El-Hani. 2014. "Function in Ecology: An Organizational Approach." Biology \& Philosophy 29:123-141.

Saul-Gershenz, L., J. Millar, J. McElfresh, and N. Williams. 2018. "Deceptive Signals and Behaviors of a Cleptoparasitic Beetle Show Local Adaptation to Different Host Bee Species." Proceedings of the National Academy of Sciences 115:9756-9760.

Thompson, John N. 1994. The Coevolutionary Process. Chicago: University of Chicago Press,. - 2005. The Geographic Mosaic of Coevolution. Chicago: University of Chicago Press. Wright, Larry. 1973. The Philosophical Review 82:139-168. 